\title{
Effect of Cooling Process on Critical Current Density of Bi-2223/Ag Superconductive Tapes Prepared by Dip-Coating
}

\author{
Masaki Sumida*, Akiyoshi Matsumoto and Hiroaki Kumakura \\ National Institute for Materials Science (NIMS), Superconducting Materials Center, Tsukuba 305-0047, Japan
}

In this paper, effect of the cooling process is examined for the superconductive properties of high $T_{\mathrm{c}} \mathrm{Bi}-2223 / \mathrm{Ag}$ tapes prepared by dipcoating. The short tapes are cooled after the isothermal heat treatment at a controlled temperature profile, which can refine the microstructure. The cooling rate and the slow cooling range are varied, showing that the optimum condition is found where the enhanced $J_{\mathrm{c}}$ is obtained compared to that of normal furnace cooling. Contrarily, $T_{\mathrm{c}}$ did not show an optimum under this condition but increased monotonously with a decrease in the cooling rate and an increase in the slow cooling range. From phase identification, microscopic observation, and quantitative analysis, the microstructure formation in the polycrystalline oxide layer during this process and its relation to these properties are discussed.

(Received June 30, 2003; Accepted July 31, 2003)

Keywords: Bi-2223, superconductor, cooling process, dip-coating, critical current density

\section{Introduction}

Material processing of the $110 \mathrm{~K}$ high $T_{\mathrm{c}}$ superconducting phase, $\mathrm{Bi}-2223\left(\mathrm{Bi}_{2} \mathrm{Sr}_{2} \mathrm{Ca}_{2} \mathrm{Cu}_{3} \mathrm{O}_{x}\right)$, has been intensely conducted since its discovery. ${ }^{1)}$ This material has a grand potential for electric current capacity at liquid nitrogen temperature. Wire applications for electric power conduction would probably bear the best engineering benefits among the potentially available applications. A powder-in-tube (PIT) technique has been widely used to fabricate $\mathrm{Bi}-2223$ cables and wires, ${ }^{2-9)}$ since the high critical current density, $J_{\mathrm{c}}$, has been successfully obtained by this method and this wireforming technique is an easy treatment for overcoming the deficit of the mechanical strength of polycrystalline oxides. $\mathrm{Ag}$ is often selected as a sheath material because it is mechanically soft and, thus, suitable for mechanical deformation, and also because its contamination does not degrade the superconductive properties. Dip-coating has been developed in this institute ${ }^{10)}$ to prepare tapes with an oxide layer on a metal substrate in uniform thickness and bulk density. Using this technique, the substrate is coated as it passes through a chemical organic solution with suspended oxide powders. Here the chemical organics burns easily during subsequent heat treatment. This technique ensures that there will be fewer sausaging and cracking problems during the mechanical deformation than those that occur with the PIT technique. This offers the potential for improvement in $J_{\mathrm{c}}$.

The phase relationship in the $\mathrm{Bi}-\mathrm{Pb}-\mathrm{Sr}-\mathrm{Ca}-\mathrm{Cu}-\mathrm{O}$ system has been investigated and compiled into diagrams by many authors. ${ }^{1-15)}$ The stability range of single Bi-2223 phase is suggested to be only within $830-845^{\circ} \mathrm{C}$ in the presence of $\mathrm{Ag}$ in air ${ }^{12)}$ and is not stable at low temperature. It forms from $\mathrm{Bi}$ $2212\left(\mathrm{Bi}_{2} \mathrm{Sr}_{2} \mathrm{Ca}_{1} \mathrm{Cu}_{2} \mathrm{O}_{y}\right), \quad(\mathrm{Ca}, \mathrm{Sr})_{2} \mathrm{CuO}_{3}, \quad(\mathrm{Ca}, \mathrm{Sr})_{2} \mathrm{PbO}_{4}$, $(\mathrm{Ca}, \mathrm{Sr})_{14} \mathrm{Cu}_{24} \mathrm{O}_{41}$, and liquid phases, and the heat treatment concentrates into this temperature range. Although this phase formation occurs peritectically, current peritectic solidification models for oxides ${ }^{16,17)}$ and metals ${ }^{18,19)}$ are not directly applied to it because of its complicated phase relationships and non-equilibrium phase formation behavior. However,

*Corresponding author, E-mail: SUMIDA.Masaki@nims.go.jp this phase formation takes place under the mechanism of the intercalation and the grain growth according to the reaction equation. Bi-2212 can be a preferential seed for the growth of Bi-2223, because of common components and similarity of crystal structure. Bi-2212 transforms into $\mathrm{Bi}-2223$ through the intercalation of $\mathrm{Ca}-\mathrm{Cu}-\mathrm{O}$. Bi-2223 thickens into the $\mathrm{Bi}$ 2212 grains while $\mathrm{Bi}-2212$ dissipates. The intercalation of $\mathrm{Ca}-\mathrm{Cu}-\mathrm{O}$ would control the rate process thus this could be very slow reaction. Bi-2223 grains surrounding Bi-2212 also grows outwards with expanding its volume. Grain growth proceeds with consuming liquid and other oxides. Because mass transportation in the mixture might control the process but that via liquid is much faster than that via solid, the amount of the liquid would determine the transformation rate. $\mathrm{Bi}-2223$ volume fraction increases with evolving both inwards and outwards of Bi-2212. Bi-2223 grains evolve preferentially along its $a-$ and $b$ - directions so that the final grain form is plate-like. Due to incompleteness of this type of reaction, $\mathrm{Bi}-2212$ and other particles remain inside and outside the $\mathrm{Bi}-2223$ grains. $\mathrm{Pb}$ doping remarkably enhances the Bi-2223 phase formation, and its optimum content for the $J_{\text {c }}$ property has been elucidated. ${ }^{20)}$ The solid solubility of $\mathrm{Pb}$ in this phase is highly temperature dependent and decreases with a decrease in the temperature below $850^{\circ} \mathrm{C}$, and $\mathrm{Bi}-2223$ can contain almost no $\mathrm{Pb}$ at $750^{\circ} \mathrm{C}$. $^{15)}$

For the applications suggested above, improvement of the $J_{\mathrm{c}}$ is of central importance. Due to polycrystalline characteristics of oxide filaments, optimization of bulk density, grain alignment and connectivity, phase composition, oxygen content, and elimination of second phase particles and microcracks are regarded as the principle goal to be achieved. Microstructure control is a crucial technique for them because their final microstructure develops during the heat treatment and mechanical deformation processes.

The slow cooling technique is effective to control the final microstructure and the $J_{\mathrm{c}}$ of Bi-2223 tapes. ${ }^{5-9)}$ Parrell et $a l^{5-7)}$ reported that the $J_{\mathrm{c}}$ of the PIT processed Bi-2223 was enhanced with a decrease in the cooling rate after an isothermal heat treatment in a low oxygen partial pressure atmosphere. Tapes were slowly cooled in the high temperature region, yielding a better intragrain flux pinning and 
intergrain connectivity. The $J_{\mathrm{c}}$ increased with a decrease in the cooling rate to $0.01{ }^{\circ} \mathrm{C} / \mathrm{min}$. Grasso et al..$^{9)}$ reported similar experiments on the PIT processed $\mathrm{Bi}-2223$ in air. The tapes were cooled from the isotherm to room temperature at a constant rate within $0.0033-8.3^{\circ} \mathrm{C} / \mathrm{min}$, and the optimum cooling rate was in the middle range at $0.16-1.6^{\circ} \mathrm{C} / \mathrm{min}$. The microstructure refined during slow cooling, however, its formation process is not fully understood, and the optimization of the cooling process on the $J_{\mathrm{c}}$ has not been completely successful.

In this report, the slow cooling technique was applied to Bi-2223 tapes prepared by dip-coating. The objective of this research is to produce tapes with better microstructure and minimum mechanical problems. The cooling rate and the slowly cooled temperature range were optimized to enhance the $J_{\mathrm{c}}$ property, and an optimum cooling condition on the $J_{\mathrm{c}}$ was found. By means of phase identification, microscopic observation, and quantitative analyses, the microstructure formation and its effect on the properties are discussed.

\section{Experimental}

Bi-2223 tapes were prepared by dip-coating. Commercial powder with a nominal composition of $\mathrm{Bi}_{1.88} \mathrm{~Pb}_{0.33} \mathrm{Sr}_{2.00} \mathrm{Ca}_{1.97} \mathrm{Cu}_{3.00} \mathrm{O}_{x}$ (Dowa co., $\sim 2 \mu \mathrm{m}$ ) was used for the starting material, which was composed mainly of $\mathrm{Bi}$ 2212 with minor $\mathrm{Bi}-2223, \mathrm{Ca}_{2} \mathrm{PbO}_{4}$, and $\mathrm{Ca}_{2} \mathrm{CuO}_{3}$. An appropriate amount of this powder was mixed with a solution of trichloroethylene, polyvinyl butyral, and sorbitantrioleate to create a viscous slurry. After being dipped into it, a $\mathrm{Ag}$ substrate of $50 \mu \mathrm{m}$ in thickness, $20 \mathrm{~mm}$ in width, and about $100 \mathrm{~cm}$ in length was pulled out at a constant rate of $1.3 \mathrm{~cm} / \mathrm{s}$ on the long axis. The mixture coated the surface of the substrate. The masking tape put on the backside of the substrate was removed after the mixture dried out in air. The oxide layer deposited finally only on one side of the substrate was $40-45 \mu \mathrm{m}$ in thickness. The tapes were divided into small pieces of $5 \mathrm{~mm} \times 30 \mathrm{~mm}$ and foiled by additional $\mathrm{Ag}$ leaves so that they would become monocore tapes. A cross section of a tape is shown schematically in Fig. 1.

Heat treatments were performed on these tapes with intermediate cold roll pressing. The entire process was completed in air. A temperature measurement in the furnace was made by a K-type thermocouple. After carefully removing the chemical organics by heat treatment at $500^{\circ} \mathrm{C}$ for 3 hours, the tapes were first pressed (RP1) to reduce their thickness to $170 \mu \mathrm{m}$ so that the bulk density would increase. The first heat treatment (HT1) was made at $T_{1}=842^{\circ} \mathrm{C}$ for

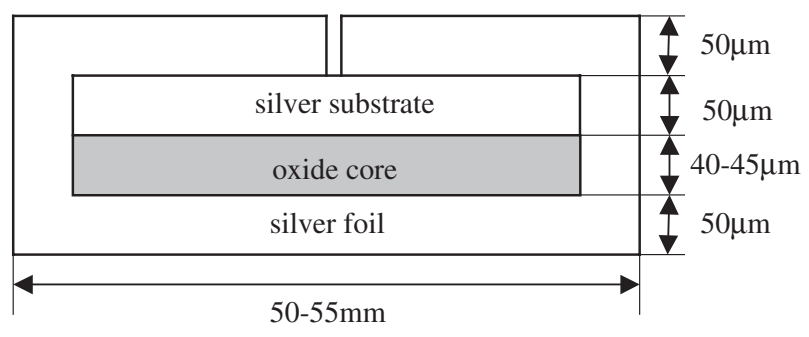

Fig. 1 Schematic illustration of a cross section of a sample tape. (a)

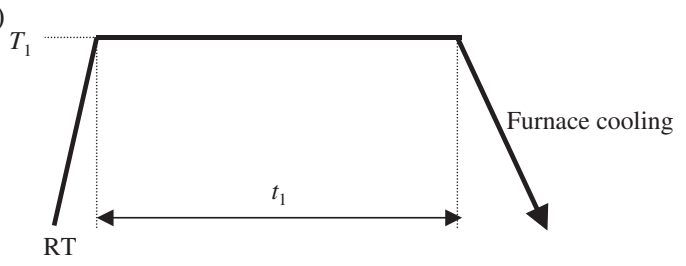

(b)

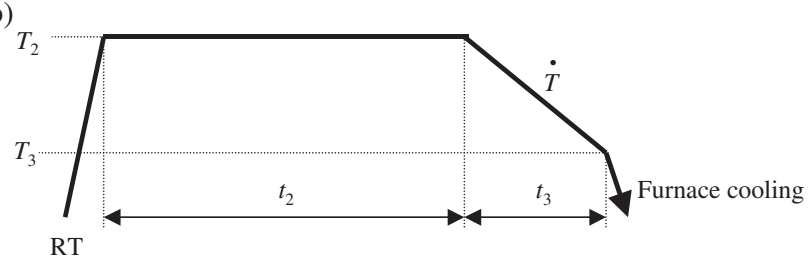

Fig. 2 Heat treatment processes in (a) the first heat treatment (HT1) and (b) the second heat treatment (HT2).

$t_{1}=96 \mathrm{~h}$ in a box furnace. After this process, the starting powder transformed mainly to $\mathrm{Bi}-2223$. The second roll pressing (RP2) was made to reduce the thickness to $90 \mu \mathrm{m}$, which was preliminarily optimized for the $J_{\mathrm{c}}$. The cross section of an oxide core was reduced to $5-10 \mu \mathrm{m}$ in thickness and spread to $5.5 \mathrm{~mm}$ in width. A dense microstructure with almost no sausaging was observed in them. The second heat treatment (HT2) was made in a horizontal tube furnace with precise temperature control. This process determines mainly the final microstructure. Because the $\mathrm{Bi}-2223$ property was very sensitive to $T_{2},{ }^{21)} T_{2}$ was taken at $836^{\circ} \mathrm{C}$ from the preliminary isothermal heat treatment experiments. The temperature histories in HT1 and HT2 are illustrated in Fig. 2. Further preliminary work was made on $t_{2}$, and the $J_{\mathrm{c}}$ increased with an increase of $t_{2}$ and was nearly constant over $t_{2}=24 \mathrm{~h}$. Then $t_{2}=96 \mathrm{~h}$ is chosen for them. After this process, the cooling rate, $\dot{T}\left(=\left(T_{2}-T_{3}\right) / t_{3}\right)$, and the lower limit of the slow cooling, $T_{3}$, in HT2 varied. $\dot{T}$ varied in the range of $0.01-5^{\circ} \mathrm{C} / \mathrm{min} . T_{3}$ varied in the range of $750-100^{\circ} \mathrm{C}$ at $\dot{T}=0.5^{\circ} \mathrm{C} / \mathrm{min}$.

The transport $J_{\mathrm{c}}$ measurements were made by four-probe method at the liquid nitrogen temperature in the self field along with $1 \mu \mathrm{V} / \mathrm{cm}$ criterion. At least three tapes were provided so that the scattering of the measured values was evaluated. The $J_{\mathrm{c}}$ was defined as the critical current divided by the cross section area of the tapes determined by the microscopic observation. The onset $T_{\mathrm{c}}$ was estimated from AC susceptibility measurements in which the measurement error is assumed to be within $1 \mathrm{~K}$ from preliminary works. $\mathrm{X}$ ray diffraction (XRD), scanning electron microscopy (SEM), and energy dispersive spectroscopy (EDS) were used for phase identification, microstructure observation, and quantitative analysis, respectively.

\section{Results}

Figure 3 shows the $J_{\mathrm{c}}$ as a function of $\dot{T}$. Samples processed with (a) $T_{3}=750^{\circ} \mathrm{C}$ and (b) $T_{3}=600^{\circ} \mathrm{C}$ are drawn. The mean values of the $J_{\mathrm{c}}$ are shown along with the error width by the maximum and the minimum of measure- 
(a)

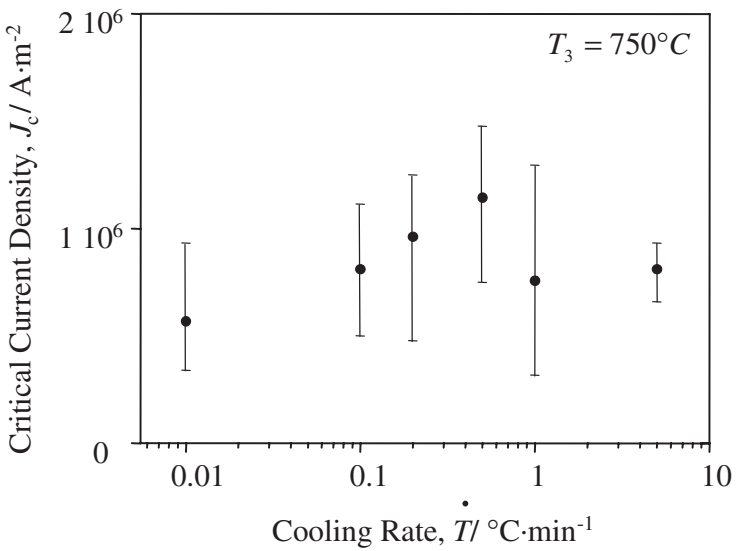

(b)

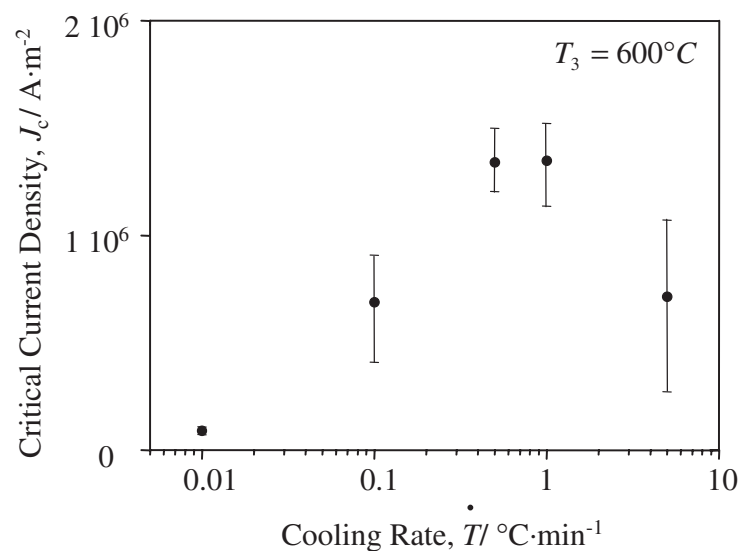

Fig. 3 The $J_{\mathrm{c}}$ of Bi-2223 tapes as a function of $\dot{T}$ with (a) $T_{3}=750^{\circ} \mathrm{C}$ and (b) $T_{3}=600^{\circ} \mathrm{C}$.

ments. The measurements well scattered even though they are processed under the same condition. This could be attributed to the local inhomogeneity of the microstructure formed during the thermo-mechanical and the measurement processes. The liquid formed locally in the core reacts with Ag to form Ag-rich compound. This forms coarse particles, which partially occupy the cross section of the core and disturb the current path. The $J_{\mathrm{c}}$ shows the maximum at $\dot{T}=0.5^{\circ} \mathrm{C} / \mathrm{min}$ for $T_{3}=750^{\circ} \mathrm{C}$, and $\dot{T}=0.5-1^{\circ} \mathrm{C} / \mathrm{min}$ for $T_{3}=600^{\circ} \mathrm{C}$. Figure 4 shows the onset $T_{\mathrm{c}}$ as a function of $\dot{T}$ with $T_{3}=750^{\circ} \mathrm{C}$. The dotted line indicates the least square

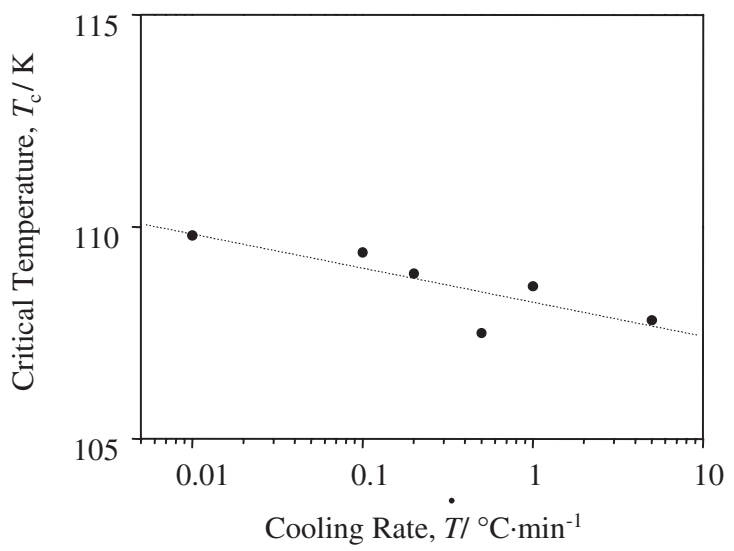

Fig. 4 The $T_{\mathrm{c}}$ of Bi-2223 tapes as a function of $\dot{T}$ with $T_{3}=750^{\circ} \mathrm{C}$.

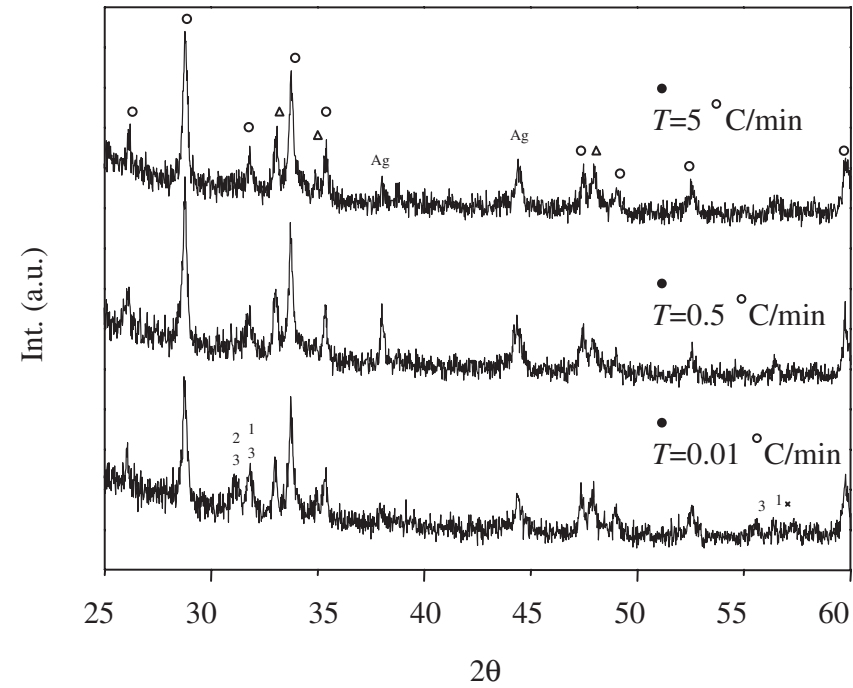

Fig. 5 XRD patterns of oxide cores in samples of $\dot{T}=5,0.5$, and $0.01^{\circ} \mathrm{C} / \mathrm{min}$ with $T_{3}=750^{\circ} \mathrm{C}$. $\circ: \mathrm{Bi}-2223, \triangle: \mathrm{Bi}-2212,1: \mathrm{Ca}_{2} \mathrm{PbO}_{4}, 2$ : $\mathrm{Sr}_{14} \mathrm{Ca}_{24} \mathrm{O}_{41}, 3: 3221$ phase and $\times$ : unknown phases.

regression. In contrast to Fig. 3 , the $T_{\mathrm{c}}$ increases slightly but monotonously with decreasing $\dot{T}$ besides one point at $\dot{T}=$ $0.5^{\circ} \mathrm{C} / \mathrm{min} . \dot{T}=0.01^{\circ} \mathrm{C} / \mathrm{min}$ shows the highest $T_{\mathrm{c}}$ of $109.8 \mathrm{~K}$ in this figure. Figure 5 shows XRD patterns of oxide cores in samples of $\dot{T}=5,0.5$, and $0.01^{\circ} \mathrm{C} / \mathrm{min}$. In this figure, intensive $\mathrm{Bi}-2223$ peaks are found in all of these patterns, showing that this is the main phase in the core. Bi-2212 is also found. This phase remains through the process due to incompleteness of the reaction. Additionally, it can also be formed during cooling, thus there are two different paths to form $\mathrm{Bi}-2212$. Small peaks of $\mathrm{Ca}_{2} \mathrm{PbO}_{4}$ are found obviously at $2 \theta=31^{\circ}$ and $57^{\circ}$ in the $\dot{T}=0.01^{\circ} \mathrm{C} / \mathrm{min}$ sample. $\mathrm{Sr}_{14} \mathrm{Ca}_{24} \mathrm{O}_{41}, 3221$ and some unknowns are also residual. Figure 6 shows corresponding SEM images in cross sections of the tapes. These microphotographs show a dense microstructure. Grain alignment is, however, not well accomplished, which could be attributed to little amount of liquid forming during the heat treatments. As observed in the central part of Fig. 6(c), $\dot{T}=0.01^{\circ} \mathrm{C} / \mathrm{min}$ yields very coarse particles. At the smaller $\dot{T}$, more and larger particles were found in the microstructure. These were identified as mainly $(\mathrm{Ca}, \mathrm{Sr})_{2} \mathrm{PbO}_{4}$ from the EDS analyses. The findings correspond with the XRD results.

Figure 7 shows the $J_{\mathrm{c}}$ as a function of $T_{3}$. Samples processed with $\dot{T}=0.5^{\circ} \mathrm{C} / \mathrm{min}$ are drawn. The $J_{\text {c }}$ shows a broad maximum at $T_{3}=450^{\circ} \mathrm{C}$. At this condition, supposing $\dot{T}=5^{\circ} \mathrm{C} / \mathrm{min}$ in Figs. 3(a) and (b) is close to the furnace cooling rate, a $J_{\mathrm{c}}$ that was about twice larger than that of furnace cooling was obtained. Figure 8 shows the onset $T_{\mathrm{c}}$ of these samples as a function of $T_{3}$. In contrast to Fig. 7, the $T_{\mathrm{c}}$ increased with decreasing $T_{3}$ slightly, besides one point at $T_{3}=600^{\circ} \mathrm{C} . T_{3}=100^{\circ} \mathrm{C}$ shows the highest $T_{\mathrm{c}}$ of $109.4 \mathrm{~K}$ in this figure. Figure 9 shows SEM images of the cross sections of $T_{3}=$ (a) $750^{\circ} \mathrm{C}$ and (b) $100^{\circ} \mathrm{C}$. A dense microstructure is observed, whereas coarse secondary particles suggested by an arrow stand out in the microstructure of $T_{3}=100^{\circ} \mathrm{C}$. 


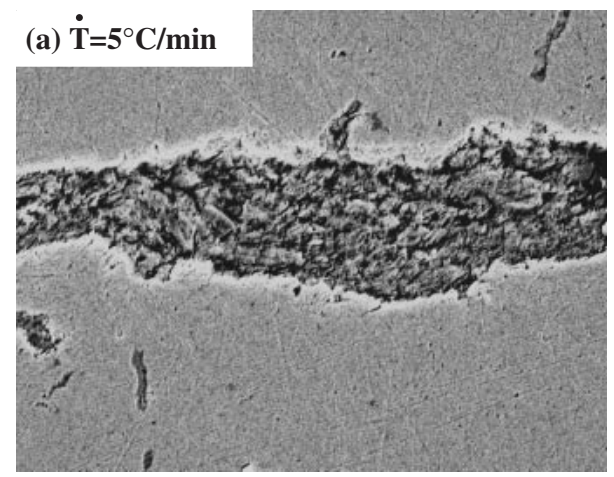

(b) $\dot{\mathrm{T}}=0.5^{\circ} \mathrm{C} / \mathrm{min}$
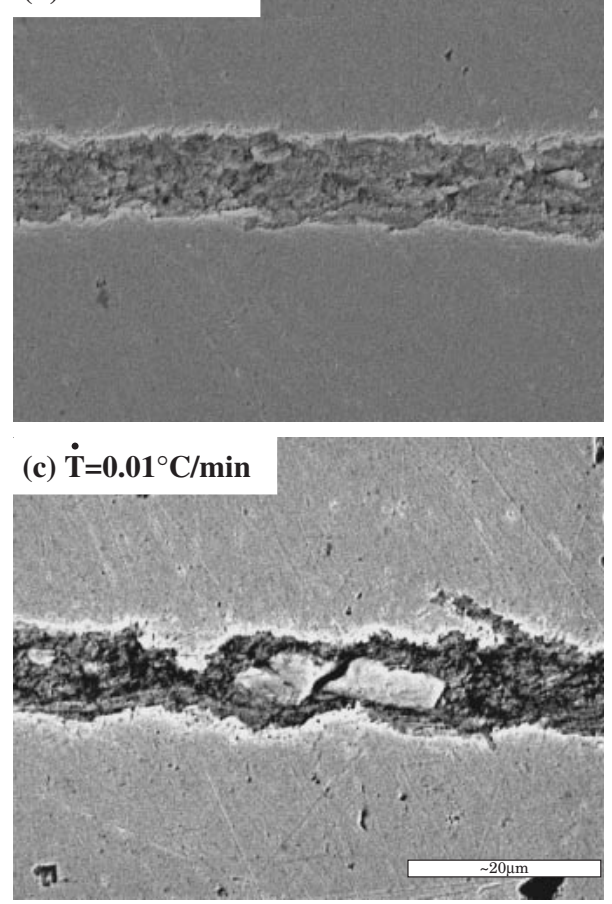

Fig. 6 SEM images of oxide cores in samples of $\dot{T}=$ (a) $5^{\circ} \mathrm{C} / \mathrm{min}$, (b) $0.5^{\circ} \mathrm{C} / \mathrm{min}$, and (c) $0.01^{\circ} \mathrm{C} / \mathrm{min}$ with $T_{3}=750^{\circ} \mathrm{C}$.

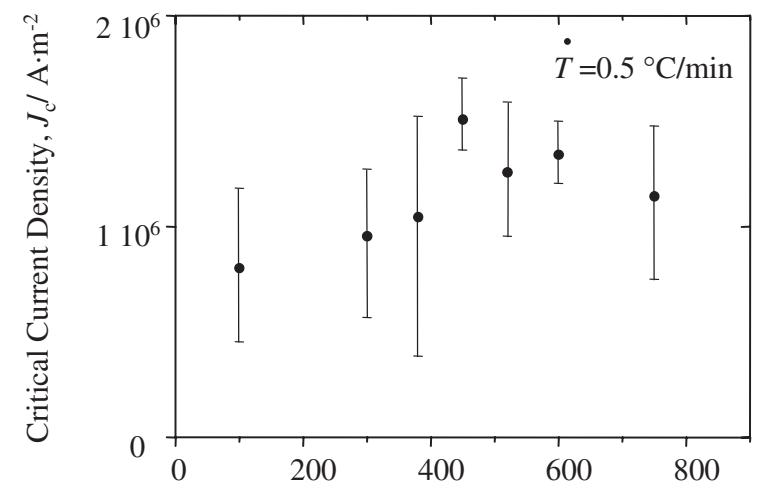

Lower Limit of Slow Cooling, $T_{3} /{ }^{\circ} \mathrm{C}$

Fig. 7 The $J_{\mathrm{c}}$ of Bi-2223 tapes as a function of $T_{3}$ with $\dot{T}=0.5^{\circ} \mathrm{C} / \mathrm{min}$.

\section{Discussion}

The $J_{\mathrm{c}}$ highly depends on the microstructure, and it is significantly determined during the cooling process. As shown in Fig. 3, the slow cooling is effective to enhance the

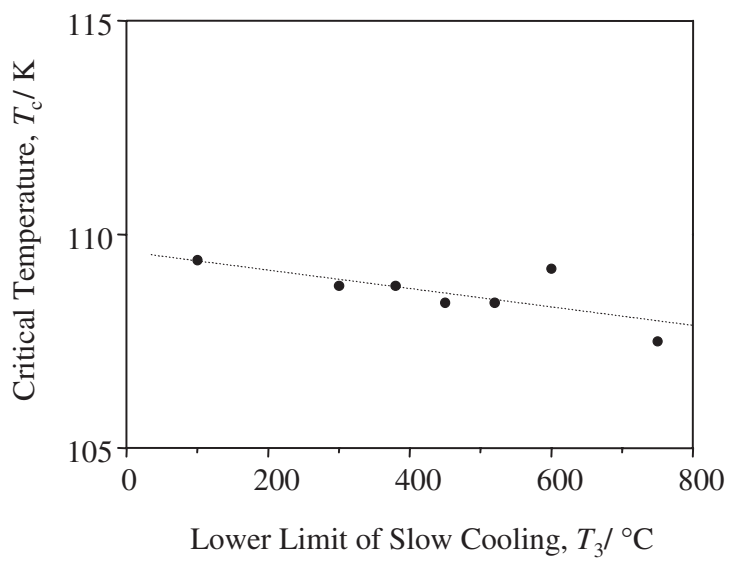

Fig. 8 The $T_{\mathrm{c}}$ of $\mathrm{Bi}-2223$ tapes as a function of $T_{3}$ with $\dot{T}=0.5^{\circ} \mathrm{C} / \mathrm{min}$.
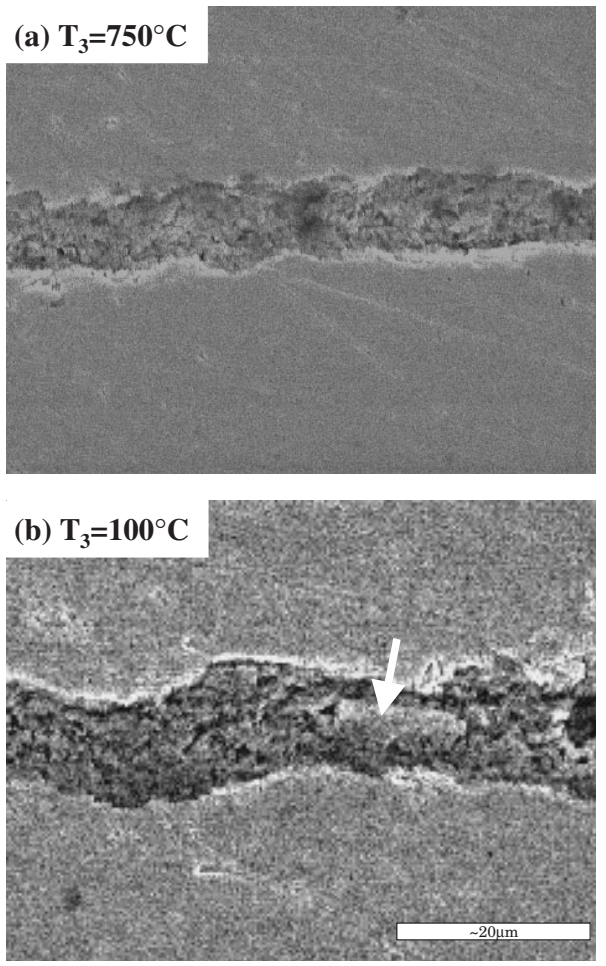

Fig. 9 SEM images of oxide cores in samples of $T_{3}=$ (a) $750^{\circ} \mathrm{C}$ and (b) $100^{\circ} \mathrm{C}$ with $\dot{T}=0.5^{\circ} \mathrm{C} / \mathrm{min}$. Coarse secondary particle is indicated by an arrow in (b).

$J_{\mathrm{c}}$, and there is an optimum range in $\dot{T}$. Comparing between Figs. 3(a) and (b), the $J_{\mathrm{c}}$ dependence on $\dot{T}$ is more significant at $T_{3}=600^{\circ} \mathrm{C}$. Parrell et al. ${ }^{7)}$ discussed the microstructure formation during slow cooling and described the factors that determine the $J_{\mathrm{c}}$. From micro- and macroscopic observations and the phase diagram, intragrain flux pinning and intergrain connectivity were specified for the $J_{\mathrm{c}}$ enhancement. Inside the grain, oxygen doping in the Bi-2223 phase, phase purification of $\mathrm{Bi}-2223$, and decomposition product to arise pinning effect occur during cooling. Concerning the grain connectivity, an increment of bulk density, reduction of residual stress, fine precipitation of secondary particles for pinning effect, and grain growth with improving the interface connectivity takes place. These can occur in the dip-coated Bi-2223 tapes to explain the $J_{\text {c }}$ increment with decrease in $\dot{T}$ 
in the range of $\dot{T}=5-0.5^{\circ} \mathrm{C} / \mathrm{min}$ in Figs. 3(a) and (b).

On the other hand, with decrease in $\dot{T}$, the cooling time, $t_{3}$, increases. $t_{3}$ takes about three hours to cool from 836 to $750^{\circ} \mathrm{C}$ at $0.5^{\circ} \mathrm{C} / \mathrm{min}$, whereas six days are required at $0.01^{\circ} \mathrm{C} / \mathrm{min}$. Purification of $\mathrm{Bi}-2223$ by rejection of $\mathrm{Pb}$ enhances with decrease in $\dot{T}$ and this may cause an increase in the $T_{\mathrm{c}}$, as shown in Fig. 5. On the other hand, because the tapes pass through the temperature range where the Bi-2223 is not stable solely, it decomposes to form the secondary phases. $\mathrm{Bi}-2212, \mathrm{Ca}_{2} \mathrm{PbO}_{4}, 3221 \mathrm{Ca}_{2} \mathrm{CuO}_{3}, \mathrm{Sr}_{14} \mathrm{Ca}_{24} \mathrm{O}_{41}$ and $\mathrm{CuO}$ can appear below the single phase stability range. $\mathrm{Bi}$ 2201 is stable at lower temperature range. Particles located at the grain boundaries are weak linkage to disturb the current path. Correspondingly, Bi-2223 volume fraction decreases due to its phase decomposition. Not all of these phases could be detected from XRD and SEM-EDS analyses, due to their small phase fraction. However, the compositional redistribution, the grain growth and decomposition considerably proceed more with decrease in $\dot{T}$. Regarding the XRD and SEM results shown in Figs. 5 and 6, the different behavior of the $J_{\mathrm{c}}$ and the $T_{\mathrm{c}}$ against $\dot{T}$ in Figs. 3 and 4 can be explained from the microstructure and composition evolution during cooling. With lowering $T_{3}$, the slow cooling range and $t_{3}$ increases proportionally. At $T_{3}=600^{\circ} \mathrm{C}$, microstructure evolution mentioned above advances more significantly relative to $T_{3}=750^{\circ} \mathrm{C}$. $t_{3}$ is longer by about three times. This results in the larger $\dot{T}$ dependence of the $J_{\mathrm{c}}$ in Fig. 3(b) than that in Fig. 3(a).

The optimum slow cooling range for the $J_{\mathrm{c}}$ is found, as shown in Fig. 7, while $T_{\mathrm{c}}$ increases with an increase in the slow cooling range, as shown in Fig. 8. The microstructure contains more secondary phases with decrease in $T_{3}$. The $J_{\mathrm{c}}$ degradation at small $T_{3}$ in Fig. 7 can be caused by these particles. However, as the equilibrium oxygen content in the $\mathrm{Bi}-2223$ is optimum below $600^{\circ} \mathrm{C}{ }^{22)}$ slow passage through this temperature range should be ideal for oxygen doping. Supposing oxygen incorporation into $\mathrm{Bi}-2223$ takes place by diffusion through grain boundary and in the grain, this process proceeds more with the residual time below $600^{\circ} \mathrm{C}$. The maximum $T_{\mathrm{c}}$ could be obtained at $T_{3}=100^{\circ} \mathrm{C}$ due to the oxygen doping by the longest cooling time.

The residual stress is reduced, and the nucleation of the fine precipitations inside the grains was enhanced, where the phases of these precipitations are stable in this temperature range. Grain growth and connectivity may be enhanced, and these would contribute to the $J_{\mathrm{c}}$ enhancement at $T_{3}=450^{\circ} \mathrm{C}$. In the light of these results, it might be concluded that the optimum cooling condition is determined by a compromise of compatible positive and negative factors during cooling.

\section{Summary}

Applying slow-cooling techniques, microstructure control was made on high $T_{\mathrm{c}}$ superconductive Bi-2223/Ag tapes prepared by dip-coating. After the thermo-mechanical process, a cooling process in the final heat treatment was varied and its effect on the microstructure and the $J_{\mathrm{c}}$ and $T_{\mathrm{c}}$ is examined. The optimum $\dot{T}$ and $T_{3}$ locate at $0.5-1^{\circ} \mathrm{C} / \mathrm{min}$ and $450^{\circ} \mathrm{C}$, respectively. On the other hand, the $T_{\mathrm{c}}$ did not show any optimum, however, it increased monotonously with a decrease in $\dot{T}$ and a decrease in $T_{3}$. The enhanced $J_{\mathrm{c}}$ about twice larger than that from the normal furnace cooling was obtained under the optimum conditions.

From phase identification, microstructure observation, and quantitative analyses, the microstructure development and the consequent different behavior of the superconductive properties against $\dot{T}$ and $T_{3}$ were discussed. The microstructure improves by pinning inside the Bi-2223 grains and connectivity of the grains with decrease in $\dot{T}$ in the large $\dot{T}$ range. In the small $\dot{T}$, it degrades with decrease in $\dot{T}$ by secondary particles formation and Bi-2223 decomposition. Possible phase purification proceeds simultaneously, however, to enhance the $T_{\mathrm{c}}$ monotonously with decrease in $\dot{T}$. With decrease in $T_{3}$, oxygen doping into the $\mathrm{Bi}-2223$ advances to enhance both the $J_{\mathrm{c}}$ and $T_{\mathrm{c}}$, where the $T_{\mathrm{c}}$ increases monotonously. In the small $T_{3}$, however, the $J_{\mathrm{c}}$ decreases with decrease in $T_{3}$ due to the degradation of the microstructure.

\section{REFERENCES}

1) H. Maeda, Y. Tanaka, M. Fukutomi and T. Asano: Jpn. J. Appl. Phys. 27 (1988) L209-210.

2) A. P. Malozemoff, W. Carter, S. Fleshler, L. Fritzemeier, Q. Li, L. Masur, P. Miles, D. Parker, R. Parrella, E. Podtburg, G. N. Riley Jr., M. Rupich, J. Scudiere and W. Zhang: IEEE Trans. Appl. Supercond. 9 (1999) 2469-2473.

3) K. Osamura, K. Ogawa, T. Thamizavel and A. Sakai: Physica C 335 (2000) 65-68.

4) J. H. Ahn, H. K. Liu and S. X. Dou: Physica C 351 (2001) 371-378.

5) J. A. Parrell, D. C. Larbalestier and S. E. Dorris: IEEE Trans. Appl. Supercond. 5 (1995) 1275-1278.

6) J. A. Parrell, D. C. Larbalestier, G. N. Riley Jr., Q. Li, R. D. Parrella and M. Teplitsky: Appl. Phys. Lett. 69 (19) 4 Nov. (1996) 2915-2917.

7) J. A. Parrell, D. C. Larbalestier, G. N. Riley Jr., Q. Li, W. L. Carter, R. D. Parrella and M. Teplitsky: J. Mater. Res. 12(11) (1997) 29973008.

8) J. P. Singh and N. Vasanthamohan: J. Mater. Res. 13(2) (1998) 261268.

9) G. Grasso, F. Grilli, A. S. Siri, F. Marti, Y. Huang and R. Flükiger: Philo. Mag. B 80(5) (2000) 991-996.

10) Y. S. Sung, H. Kumakura and K. Togano: Physica C 331 (2000) 171177.

11) P. Strobel, J. C. Tolédano, D. Morin, J. Schneck, G. Vacquier, O. Monnereau, J. Primot and T. Fournier: Physica C 201 (1992) 27-42.

12) W. Wong-Ng, L. P. Cook and W. Greenwood: J. Mater. Res. 14(5) (1999) 1695-1706.

13) W. Wong-Ng, L. P. Cook, A. Kearsley and W. Greenwood: J. Res. Natl. Inst. Stand. Tech. 104 (1999) 277-289.

14) R. J. Moon, K. P. Trumble and K. J. Bowman: J. Mater. Res. 14(3) (1999) 652-664.

15) P. Majewski: J. Mater. Res. 15(4) (2000) 854-870.

16) M. Sumida, Y. Shiohara and T. Umeda: Metall. Mater. Trans. 31B (2000) 141-149.

17) M. Sumida and T. Umeda: Metall. Mater. Trans. 32A (2001) 595-604.

18) M. Sumida: J. Alloy. Compd. 349 (2003) 302-310.

19) M. Sumida: Mater. Trans. 44 (2003) 1351-1358.

20) J. W. Anderson, S. E. Dorris, J. A. Parrell and D. C. Larbalestier: J. Mater. Res. 14(2) (1999) 340-348.

21) E. A. Young, Y. Yang, C. Beduz and R. Riddle: IEEE Trans. Appl. Supercond. 11(1) (2001) 2979-2982.

22) Y. Idemoto, S. Ichikawa and K. Fueki: Physica C 181 (1991) 171-178. 